\title{
O ensino ativo dos Trabalhos Manuais no curso primário paulista: um estudo da escolarização dos saberes matemáticos
}

\author{
Claudia Regina Boen Frizzarini* \\ Maria Célia Leme da Silva**
}

\section{Resumo}

O presente artigo tem o intuito de construir uma primeira representação sobre o ensino da matéria escolar Trabalhos Manuais no curso primário de São Paulo a partir de sua relação com os saberes matemáticos. O estudo amparado pelo ferramental teórico metodológico da História Cultural identifica duas grandes finalidades, que dizem respeito aos saberes matemáticos, atribuídas ao ensino de tal matéria: na primeira, os Trabalhos Manuais têm como função auxiliar o processo de compreensão dos saberes geométricos, que funciona como um "método de ensino" para aprender saberes matemáticos; na segunda, os Trabalhos Manuais como utilização de saberes matemáticos estudados em outras matérias para a formação do trabalhador, de um ofício ao aluno. Desse modo, uma representação dos Trabalhos Manuais no curso primário paulista seria a compreensão das relações desta matéria com os saberes matemáticos como uma via de mão dupla, em que um saber auxilia o outro e contribui a concretizar o ensino moral, físico, intelectual e profissional, de modo prático e intuitivo.

Palavras-chave: Trabalhos Manuais. Ensino Primário. Finalidades da Educação.

\footnotetext{
* Mestre e Doutoranda em Educação e Saúde na Infância e Adolescência na Universidade Federal de São Paulo (UNIFESP). ** Doutora em Educação pela Pontifícia Universidade Católica de São Paulo (PUC/SP). Professora do Departamento de Ciências Exatas e da Terra e do Programa de Pós-Graduação em Educação e Saúde na Infância e Adolescência na Universidade Federal de São Paulo (UNIFESP).
} 


\section{Um tempo, um lugar, um saber...}

Os livros de história nos relatam sobre a evolução do nosso país, apresentam os avanços advindos com a Proclamação da República em 15 de outubro de 1889 e com os diversos movimentos políticos pelos quais passamos, entretanto, pouco é difundido sobre as inovações e mudanças observadas no ensino.

Pensar a escola de antigamente, seus prédios, mobiliário, vestimentas dos alunos, instiga-nos a investigar sobre o que se ensinava nos séculos passados, que matérias, conteúdos e metodologias eram propostos aos alunos do curso primário. Nessa reflexão sobre o ensino brasileiro, mais especificamente no período de 1889 a 1930, o olhar micro às escolas paulistas torna-se macro, o estado é pioneiro na difusão de um novo modelo de escola primária, os Grupos Escolares, que, criados em 1893, trazem consigo inovações na organização do espaço escolar, na metodologia e nos conteúdos de ensino.

Sendo assim, delimitamos um tempo, o período da Primeira República; um lugar, o estado de São Paulo; e o saber, que remete ao fazer e a prática, noções muito presentes nessa época difundidas pelo movimento da Pedagogia Moderna ${ }^{1}$ e presentes em abundância nos programas primários paulistas na matéria Trabalhos Manuais. Tal escolha decorre do resultado da pesquisa de mestrado "Do ensino intuitivo para a escola ativa: os saberes geométricos nos programas do curso primário paulista, 1890 1950" (FRIZZARINI, 2014). Nesse estudo foi realizada uma análise acerca das matérias escolares que envolviam saberes geométricos nos programas primários paulistas e uma matéria em especial se destacou pela presença assídua em todos os programas e sua visível relação com os saberes matemáticos, a partir de atividades de recorte de figuras planas, modelagem, cartonagem e dobradura de sólidos geométricos, os Trabalhos Manuais evidenciavam o manuseio, a prática e a atividade proposta diretamente ao aluno, grande marca da vaga pedagógica recorrente do método intuitivo, a Pedagogia Moderna.

Desse modo, o presente artigo ${ }^{2}$, amparado pelo referencial teórico metodológico advindo da História $\mathrm{Cultural}^{3}$, buscará construir uma representação histórica das propostas de ensino da matéria Trabalho Manual nas escolas primárias paulistas, com ênfase no elo prático desenvolvido com o aluno e sua relação com os saberes matemáticos, no período de 1889 a 1930, em que a Pedagogia Moderna e o método intuitivo traçam as diretrizes ao ensino paulista. 


\section{Pedagogia Moderna: a busca por um ensino ativo}

No final do século XIX, os debates em prol da renovação do ensino primário ocorriam fervorosos em toda parte do mundo. O descontentamento com a instrução tradicional, baseada na memorização, abstração e repetição, atravessou o Atlântico e atracou no Brasil com os princípios de um novo movimento educacional, a Pedagogia Moderna.

Rui Barbosa ${ }^{4}$, polímata e grande conhecedor da realidade brasileira e europeia, é convidado em 1883 a redigir pareceres sobre a instrução pública e, nestes, divulga e recomenda com veemência o método intuitivo como meio de renovação aos mestres, aos alunos e ao ensino como um todo.

O parecer Reforma do ensino primário e várias instituições complementares da instrução pública, especificamente em seu tomo II, apresenta a insatisfação com o ensino de mais de três séculos, “ensino vão, abstrato, morto, de palavras, palavras e só palavras” (BARBOSA, 1946, p. 199). De outra parte, Barbosa expõe leituras de antigos pensadores e educadores sobre uma nova forma de pensar o ensino, tal como as ideias de Lutero, Bacon, Ratke e Comenius, que apontam o ensino pela evidência, pela intuição, pelas coisas:

É pela intuição real, não por descrições verbais, que o ensino deve começar. [...] Habituemo-nos, quanto ser possa, a formar a ciência, nos moços, não extraindo-a dos livros, mas da contemplação do céu e da terra. Isto é, ensinando-os a perceberem, e escrutarem [sic] diretamente as coisas. Os objetos da instrução natural sejam coisas sólidas, reais, uteis, capazes de atuar nos sentidos e na imaginação: obtem-se este resultado, aproximando as coisas aos sentidos, tornando-as visíveis aos olhos, audíveis ao ouvido, cheirosas ao olfato, saborosas ao paladar, sensíveis ao tato. Pelos sentidos há de principiar a instrução. (BARBOSA, 1946, p. 202-203) .

São propostas desenvolvidas pelas mãos de Pestalozzi e Buisson, que, segundo Barbosa (1946), definiram os limites entre o mestre e o aluno, e entre o aluno e sua instrução:

Não é outro o segredo do método intuitivo, senão tratar o menino como criatura, que possue em si mesma o instinto do saber e todas as faculdades precisas para o adquirir: o seu empenho está em deixar entregue a si própria a natureza, tanto quanto ser possa. Sem dúvida, nem sempre a natureza será suficiente a si mesma; mas, ao menos, não a descorçoemos. (BUISSON apud BARBOSA, 1946, p. 214).

Zanatta (2012) sintetiza, a partir das falas de Barbosa (1946) e Buisson (apud BARBOSA 1946), que a base do método intuitivo se situa no princípio de percepção sensorial, obtida através da relação homem-natureza. Inicia-se pelo contato direto dos sentidos com os objetos e, a partir das 
impressões obtidas dessa observação, permite-se a atividade mental expressa em palavras. O ensino pelo método intuitivo se alicerça, então, pela projeção do mundo exterior, constitui-se de fora (das coisas) para dentro.

No Brasil, o método intuitivo começa a ganhar força no final do século XIX. O Decreto $\mathrm{n}^{\circ}$ 7247, de 19 de abril de 1879 (BRASIL, 1879), redigido pelo ministro Carlos Leôncio de Carvalho, já introduzia nas escolas populares as lições de coisas, entretanto, segundo Barbosa (1946), foi proposto de modo errôneo, como uma matéria independente no programa, em que nada contribuiria para o ensino, pois as lições de coisas tratam-se um método de ensino que deveria abranger o programa inteiro. Mas será que a proposta de Barbosa (1946) de levar as lições de coisas como um método de ensino a ser desenvolvido em todo o programa realmente ocorreu? Como as lições de coisas foram apropriadas nas diferentes matérias de ensino, em particular, nos Trabalhos Manuais?

Para responder a tais questões, como já explicitado anteriormente, devemos levar em conta que no período da Primeira República, os olhares para o ensino centralizam-se em São Paulo, e este se torna modelo da instrução pública a todo o país. Na busca pela modernização do ensino paulista, o Presidente do estado, Bernardino de Campos, aprova a Lei $\mathrm{n}^{\circ}$ 88, de 8 de setembro de 1892, em que, segundo seu artigo 5, "cada escola preliminar, além de uma área bastante espaços, para recreios e exeriícios physicos, terá uma sala apropriada para os trabalhos manuaes e os objectos e apparelhos necessarios para o ensino intuitivo, para o da geographia, do systema metrico e da gimnastica" (SÃO PAULO, 1892).

Posteriormente, em 1893, a partir da reforma de instrução pública instaurada pela Lei $n^{\circ} 88$ (BRASIL, 1892), um novo modelo de escola primária é proposto: os Grupos Escolares. Mais que monumentos arquitetônicos construídos propriamente para o ensino, os Grupos tinham como finalidade organizar os alunos por idade e série, de modo a homogeneizar o ensino.

Os Grupos Escolares de São Paulo revelam, então, uma nova apresentação da escolarização. Se antes o controle do estado recaía apenas sobre a estrutura do programa - as matérias a serem ensinadas -, a partir de então indicações cada vez mais detalhadas se voltam para a normatização dos programas escolares (SOUZA, 2009).

No período de 1893 a 1930 foram regulamentados por decretos cinco programas para os cursos primários. Datados de 1894, 1905, 1918, 1921 e 1925, os programas revelam suas relações com o método intuitivo, as lições de coisas, mais especificamente na matéria em que o fazer é mais promovido: os Trabalhos Manuais. 


\section{Os Trabalhos Manuais nos programas primários paulistas (1894-1925)}

Em 26 de julho de 1894, o ainda Presidente do estado de São Paulo, Bernardino de Campos, aprova o Decreto $\mathrm{n}^{\mathrm{o}} 248$, que estabelece o primeiro programa aos Grupos Escolares paulistas (SÃO PAULO, 1894). Elaborado por Oscar Thompson, Benedito Tolosa e Antonio Rodrigues Alves ${ }^{6}$, o programa segue a oficialização do decreto que, em seu capítulo I dedicado ao ensino, institui:

Artigo 9. ${ }^{\circ}$ - As licções sobre as materias de qualquer dos annos do curso deverão ser mais empíricas e concretas do que theoricas e abstractas e encaminhadas de modo que as faculdades infantis sejam provocadas a um desenvolvimento gradual e harmonico.

Artigo $10 .^{\circ}$ - O professor deverá ter em vista, principalmente, desenvolver a faculdade de observação, empregando para isso os processos intuitivos. (SÃO PAULO, 1894, grifo nosso).

A indicação do uso do método intuitivo está presente na condução do ensino, mas será que ele ainda é proposto como no decreto imperial de 1879, em que as lições de coisas constituíam uma matéria no programa? A resposta é não! O programa de 1894 é totalmente reformulado e muito difere das prescrições imperiais.

Dividido em quatro anos, de modo vasto e detalhado, o programa, além de estabelecer direções gerais sobre o ensino, delimita o que deverá ser ensinado a cada série e ano e não apresenta a matéria lições de coisas em separado. As lições de coisas passam a ser compreendidas do modo como Rui Barbosa prescrevia, como um método de ensinar todas as matérias escolares, ferramenta do método intuitivo.

O método é aludido referenciando a necessidade de uma sala apropriada para o ensino dos Trabalhos Manuais, além de objetos e aparelhos para o ensino intuitivo. Juntamente com a menção sobre o método a utilizar, está ressaltada a importância do ensino dos Trabalhos Manuais, na necessidade de se obter uma sala especial para a execução de suas atividades. Mas qual seria a finalidade $^{7}$ dos Trabalhos Manuais nesse programa? Os Trabalhos Manuais de 1894 revelam nas normativas dos conteúdos apropriações ${ }^{8}$ do método intuitivo?

Como já dito, o programa de 1894 descreve os conteúdos de modo detalhado e assim podemos identificar a proposta de ensino gradativo dos Trabalhos Manuais. As atividades iniciam no primeiro ano com trabalhos em papel (relativos à dobradura e à tecelagem), no segundo ano seguem os exercícios com papel, agora relativos ao recorte e trabalhos de tecelagem mais complexos envolvendo 
tranças, além da modelagem de objetos que lembrem sólidos geométricos. Posteriormente, no terceiro ano são apresentados exercícios em vime (similares aos de tecelagem antes realizados em papel) e trabalhos de cartonagem (construção de figuras geométricas com escalas), finalizam-se os estudos no quarto ano com trabalhos em madeira e ferro. Para as meninas são acrescidos, desde o segundo ano, as noções básicas de elementos de costura, além de trabalhos em crochê, tricô e bordados.

Além dessas atividades propostas a partir de uma miscelânea de materiais e instrumentos, outra matéria ${ }^{9}$ contribui ao ensino de atividades manuais, a Modelagem. Essa é apresentada nos três primeiros anos e, de modo sucinto, propõe a construção em papel e modelagem em barro úmido de sólidos geométricos e outros objetos que lembrem a forma desses sólidos.

Uma primeira análise desses conteúdos, tanto referente aos Trabalhos Manuais quanto à Modelagem, indica que existem evidências dos preceitos da Pedagogia Moderna nos conteúdos apontados no programa de 1894. Ou seja, Tolosa, Thompson e Rodrigues Alves criaram suas próprias representações ${ }^{10}$ dessa pedagogia e a desenvolvem no programa. Essa suposição decorre da forma como os conteúdos são apresentados, seguem a proposta pestalozziana, do mais simples ao mais complexo, e, mais ainda, remetem à natureza da criança ao propor, por exemplo, o ensino da modelagem iniciando pelas formas da esfera, cubo e cilindro, figuras sólidas presentes na vida cotidiana do aluno, nas bolas, nos dados e nas latas, respectivamente.

Mais ainda, não se pode perder de vista que os autores do programa criaram e editoraram em 1893 a revista $A$ Eschola Publica, que traz de berço as apropriações da modernidade pedagógica e dissemina suas raízes advindas da Pedagogia Moderna e do método intuitivo por ela difundido. A revista é voltada para a inovação educacional, mediante abordagem das questões e conteúdos do ensino das matérias do programa da escola primária, e representativo de importantes transformações ocorridas no âmbito educacional paulista.

Figura 1 - Capa da revista A Eschola Publica

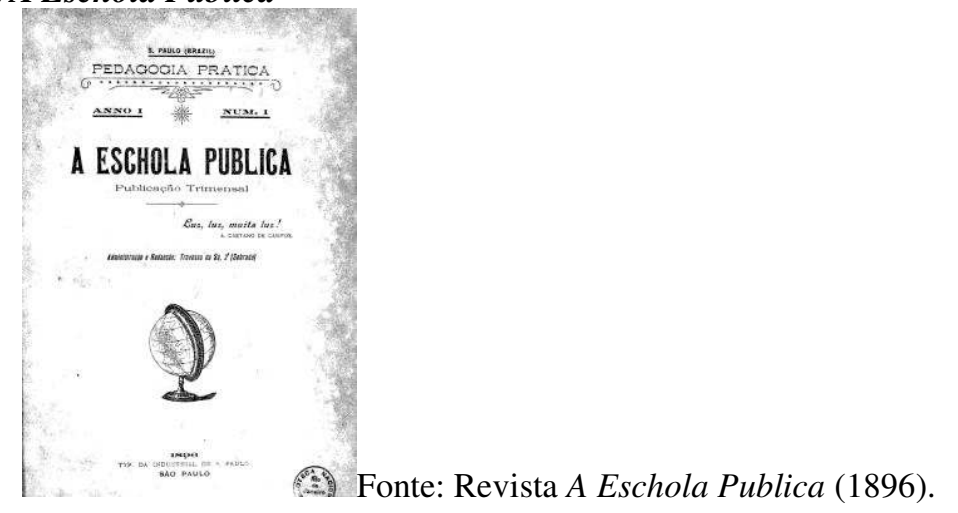

PERSPECTIVA, Florianópolis, v. 34, n. 1, p. 119-141, jan./abr. 2016

http://www.perspectiva.ufsc.br 
As edições de 1896 a 1897, relativo a uma segunda fase da revista, dispõe de oito publicações em que foram encontrados nove artigos referentes aos Trabalhos Manuais, sendo sete de Alfredo Bresser $^{11}$, que fornecem modelos de lições das matérias de ensino, e dois de Ramon Roca ${ }^{12}$, dedicados à explicação da importância dos trabalhos manuais.

Os artigos de Bresser encontram-se em uma seção especial da revista chamada Pedagogia Pratica; sobre Trabalhos Manuais são abordadas e exemplificadas atividades de dobraduras, recorte, tecido, cartonagem e modelagem. Segundo Carvalho (2011), esses artigos de Pedagogia Pratica fornecem ao professor coisas para usar, como se tratasse de uma caixa de utensílios, que remetem à concepção adotada pela Pedagogia Moderna, em que a imitação de práticas exemplares é identificada como princípio no qual ensinar a ensinar é entendido como fornecer bons moldes e é isso que a revista preza.

As atividades de Trabalhos Manuais apresentadas por Bresser revelam a aproximação das mesmas com o programa de 1894, e em todo momento é ressaltada a gradação do ensino paralelamente ao programa. Além disso, os indícios da Pedagogia Moderna podem ser observados vivamente nos textos de Trabalhos Manuais de Alfredo Bresser, nos exercícios que devem ser executados com perfeição e asseio pelo aluno, a partir da observação atenta dos movimentos e ordens do professor em atividades que estão presentes, muitas vezes, na vida cotidiana do aluno.

É interessante ressaltar que para desempenhar os exercícios e atividades de Trabalhos Manuais, tanto os propostos na revista A Eschola Publica quanto os conteúdos apresentados no programa de 1894, muito se recorre aos conceitos e termos utilizados nas matérias de Geometria, Forma e Desenho, pois a todo tempo se utiliza de sólidos geométricos e figuras planas para construção das atividades e de noções de ângulos e quinas com a intenção de obtê-las de modo perfeito.

Clara está a proximidade entre as matérias de Trabalhos Manuais e aquelas específicas de saberes geométricos, entretanto, é preciso compreender as finalidades e relações entre tais matérias, nesse sentido, duas possibilidades se evidenciam: a execução dos Trabalhos Manuais como auxiliar na compreensão de saberes matemáticos; ou os Trabalhos Manuais como utilização de exemplos de saberes matemáticos estudados nas matérias de Geometria, Forma e Desenho.

Com a virada do século um novo programa é proposto aos Grupos Escolares de São Paulo pelo Decreto $\mathrm{n}^{\mathrm{O}}$ 1281, de 24 de abril de 1905 (SÃO PAULO, 1905). Aprovado pelo presidente do estado Jorge Tibiriçá Piratininga, o programa de 1905 tem como autores, novamente Oscar Thompson e agora 
Horácio Manley Lane ${ }^{13}$. Estes nomes evidenciam a relação do programa com a Pedagogia Moderna, visto que Lane é um dos precursores da Escola Americana no Brasil, uma das primeiras instituições brasileiras a adotar o método intuitivo (SHIEH, 2010).

Com a estratégia de disseminar os princípios do protestantismo ao povo brasileiro, os protestantes elegeram a educação como meio de consolidar sua doutrina. Não demorou muito para que o ensino desenvolvido na Escola Americana, mantida pelos protestantes, fosse visto pela elite paulista como um ensino de qualidade, adepto das mais modernas técnicas pedagógicas, com um currículo seriado e diversificado, aderente do método intuitivo (PINHEIRO, 2013).

Além disso, o programa de 1905 segue normativas anteriores de 1904 (referentes à Lei no 930 e ao Decreto $\mathrm{n}^{\mathrm{o}}$ 1239), em que é instituído que o ensino deve seguir os princípios do método intuitivo e que o programa utilizado deve ser determinado pelo governo. Assim, pela influência de seus autores e por leis anteriores, o programa não poderia seguir qualquer outro método a não ser o intuitivo.

O programa de 1905 muito difere do anterior de 1894, que obteve largas críticas devido a sua extensão e abrangência de maneira a desconsiderar as condições materiais. Para os professores em exercício, a execução do programa requeria “[...] uma ordenação curricular estruturada sobre uma arquitetura temporal presidida por uma lógica assentada na homogeneidade e simultaneidade dos ritmos de aprendizagem dos alunos" (SOUZA, 2009, p. 84). Tais imposições retiravam a independência dos professores e, diante dessa situação, o programa de 1894 tornou-se inexequível aos Grupos Escolares.

Desse modo, com quatro anos de duração, menos matérias e conteúdos mais sucintos, o programa de 1905 é diretivo na prescrição dos conteúdos, os Trabalhos Manuais agora passam a ser divididos em três tipos: trabalho para ambos os sexos, trabalhos exclusivos ao sexo masculino e trabalhos exclusivos ao sexo feminino. Nesse programa identificamos uma diferenciação de trabalhos próprios aos meninos e às meninas, algo que antes não era proposto. Em 1894 os trabalhos eram comuns, somente acrescentado às meninas as noções de costura e bordados.

A proposta de ensino graduado, do mais simples ao mais complexo, segue na direção dos conteúdos elencados, os trabalhos comuns às meninas e aos meninos são indicados até o segundo ano, iniciam com exercícios em papel (dobradura e tecelagem) e modelagem da esfera, cubo e cilindro (formas de objetos conhecidos às crianças) e, no segundo ano, propõe-se alinhavos e modelagem de figuras geométricas. Nesses dois primeiros anos ainda é proposto às meninas alguns exercícios simples de costura e crochê. 
A matéria Modelagem de 1894 integra-se à matéria de Trabalhos Manuais de 1905, ou seja, os conteúdos de Modelagem são incorporados aos de Trabalhos Manuais. Para os dois primeiros anos, destinados aos meninos e às meninas, são propostas atividades com modelagem em que o aluno deverá identificar e compreender as formas geométricas da esfera, cubo e cilindro. Fica evidenciada a importância do manuseio de moldes práticos construídos em formas geométricas, para que o aluno compreenda as diferenças entre a esfera, o cubo e o cilindro.

Assim sendo, tudo indica que a finalidade dos Trabalhos Manuais, nos dois primeiros anos e para ambos os gêneros, está posta como auxiliar na compreensão dos saberes geométricos, ou seja, os Trabalhos Manuais têm como função participar do processo de ensino de saberes geométricos, é um “método de ensino" para a aquisição de saberes. A prática de modelagem é o fio condutor no método de ensino.

Para o terceiro e quarto anos, o programa é diferenciado por gênero. Para os meninos, o programa apresenta como conteúdos as modelagens de figuras geométricas e objetos usuais, além da cartonagem de sólidos geométricos e exercícios básicos de carpintaria. Para as meninas, o programa indica a continuação dos exercícios de costura e crochê, mais específicos e detalhados.

A divisão de conteúdos e abordagens para meninos e meninas remete, uma vez mais, à análise sobre a finalidade dessa matéria, especificamente no programa de 1905. A diferenciação de gênero implica, obrigatoriamente, em uma diferenciação da matéria, de modo que a finalidade dos Trabalhos Manuais se altera diante da separação posta entre meninos e meninas. Segundo Souza (2000), as matérias desenvolvidas no curso primário são resultado da escolarização de saberes profissionais, sociais e científicos, com a intenção de formar o futuro trabalhador. Ou melhor, futuros trabalhadores, devido à diferenciação entre saberes profissionais para o futuro trabalhador e a futura trabalhadora; o menino lida com exercícios de carpintaria e cartonagem para lhe fornecer destreza na mão e nos olhos e apreço ao trabalho com madeira; a menina faz costuras cada vez mais elaboradas, que segundo Lebeaume (2010), revelam a função de sua formação: obter a tríade mãe-mulher-esposa, intimamente ligada às noções de higiene (confecção de toalhas, babadores, aventais, lenços), e economia doméstica (aplicação de remendos).

A finalidade dos Trabalhos Manuais com vista à formação profissional, diferenciando-se segundo o gênero, está posta como aplicação de saberes matemáticos estudados em outras matérias e mesmo nos dois anos iniciais de Trabalhos Manuais para construção de objetos para a formação 
profissional. A prática é regida por necessidades de ordem profissional e social e não particularmente do saber escolar.

Treze anos após o programa de 1905 é aprovado, em 8 de agosto de 1918, um novo programa aos Grupos Escolares paulistas através do Decreto n ${ }^{\circ} 2944$ (SÃO PAULO, 1918). Assinado pelo Presidente do estado de São Paulo, Altino Arantes, e pelo Secretário dos Negócios do Interior, Oscar Rodrigues Alves, este se apresenta de modo sucinto, somente com a prescrição dos conteúdos exigidos a cada matéria, nem sequer é abordado o método de ensino a ser utilizado ou como deveriam ser direcionadas as atividades.

As atividades desse programa também se diferenciam aos meninos e às meninas, mas tal divisão não ocorre como no programa anterior, em que nos dois primeiros anos as atividades eram similares e nos dois últimos havia a cisão de gênero (Quadro 1).

\section{Quadro 1 - Conteúdos de Trabalhos Manuais no programa de 1918}

\begin{tabular}{|c|c|c|}
\hline & DIVISÃO & CONTEÚDOS \\
\hline \multirow[t]{2}{*}{$\begin{array}{c}\mathbf{1}^{\mathbf{o}} \\
\text { ano }\end{array}$} & Trabalhos comuns & $\begin{array}{l}\text { Dobramento de papel. Objetos usuais: chapéus, barquinhas, } \\
\text { caixinhas etc. } \\
\text { Tecidos de papel. Alinhamento em cartões, à vista de modelos } \\
\text { apropriados e graduados. Modelo: construção de formas } \\
\text { geométricas já estudadas. }\end{array}$ \\
\hline & Acresce às meninas & Posição das mãos e modos de segurar a agulha. Crochê simples. \\
\hline \multirow{2}{*}{$\begin{array}{c}2^{\mathbf{o}} \\
\text { ano }\end{array}$} & $\begin{array}{l}\text { Trabalhos para os } \\
\text { meninos }\end{array}$ & $\begin{array}{l}\text { Alinhavos em cartão, executados a cores, sobre modelos diversos, } \\
\text { representando figuras de animais, flores e outros motivos } \\
\text { decorativos. Modelagem de objetos usuais. }\end{array}$ \\
\hline & $\begin{array}{l}\text { Trabalhos para as } \\
\text { meninas }\end{array}$ & $\begin{array}{l}\text { Crochê, pontos, alinhavos, pós-pontos, pós-pontos no claro, pontos } \\
\text { fechados e abertos, pontos de remate. Preparação e modo de franzir. } \\
\text { Franzidos duplos. }\end{array}$ \\
\hline \multirow{2}{*}{$\begin{array}{c}3^{\circ} \\
\text { ano }\end{array}$} & Trabalhos comuns & $\begin{array}{l}\text { Trabalhos de horticultura e de jardinagem. Aplicação manual das } \\
\text { folhas, ramos, fibras, lenhosas, vime, cipó, couros, pele, penas etc. }\end{array}$ \\
\hline & Acresce às meninas & Costura, cerziduras, franjas, malhas, alinhavos, remendos etc. \\
\hline \multirow{2}{*}{$\begin{array}{c}4^{\mathbf{o}} \\
\text { ano }\end{array}$} & $\begin{array}{l}\text { Trabalhos para os } \\
\text { meninos }\end{array}$ & $\begin{array}{l}\text { Reprodução de sólidos geométricos e objetos simples, em argila. } \\
\text { Objetos usuais, em madeira, como corta-papel, enquadros, cunhas, } \\
\text { réguas, cantoneiras, estantes simples etc. Exercícios de cartonagem. }\end{array}$ \\
\hline & $\begin{array}{l}\text { Trabalhos para as } \\
\text { meninas }\end{array}$ & $\begin{array}{l}\text { Ponto russo e de ornamentos. Pontos de marca, letra e nomes. } \\
\text { Camisas, aventais, lenços, toalhas, babadouros etc., para aplicação } \\
\text { de estudos anteriores. }\end{array}$ \\
\hline
\end{tabular}

Fonte: São Paulo (1918).

Assim, a análise do programa de 1918, em relação à matéria Trabalhos Manuais, indica, de maneira tímida, que a relação dos Trabalhos Manuais como suporte ao ensino dos saberes matemáticos não é perdida. Nas atividades comuns para meninos e meninas, a modelagem reitera seu caráter de 
prática "formadora" de conceitos geométricos. Nos dois anos finais, os conteúdos empregados destinam-se quase que exclusivamente à função de formar o futuro trabalhador, ora em fazeres próprios das meninas e meninos, ora em atividades comuns (tal como a horticultura, que fornece subsídios à formação para o homem no campo e para a mulher-mãe-esposa).

A Revista de Ensino (Figura 2), órgão da Associação Beneficente do Professorado Publico de S. Paulo e sob os auspícios da Diretoria Geral da Instrução Publica, com publicações trimestrais desde 1902 até 1919, apresenta, em uma publicação específica dos números 3 e 4, de dezembro de 1917 e março de 1918, dois artigos que contribuem para a reflexão sobre essas formações "de ofícios".

Figura 2- Capa da Revista de Ensino

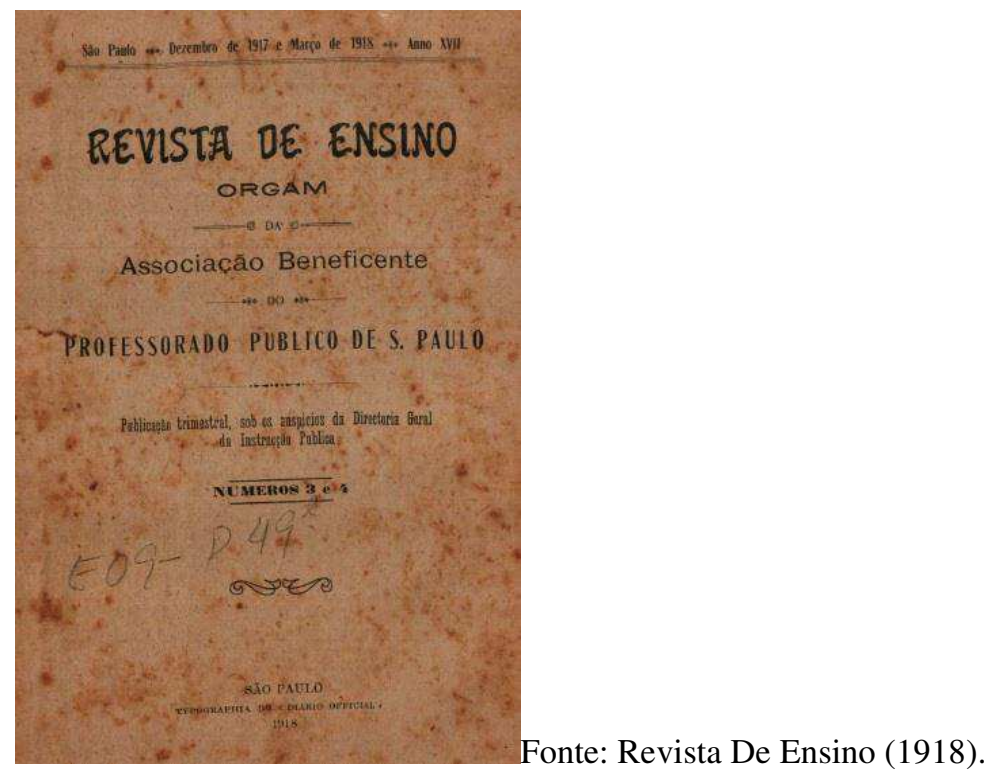

Carlos da Silveira ${ }^{14}$ (1918, p. 36), em seu artigo "Da educação e dos educadores”, estabelece uma linha cronológica do objetivo da educação e chega até o ano de 1918, no qual é publicado o texto, afirmando que “[...] o fim da educação é hoje, portanto, criar o homem productor de riqueza, o cidadão forte para o trabalho, beneficiando-se a si próprio e á collectividade de que é parte".

Vislumbrada a finalidade do ensino, Silveira (1918, p. 36) traz ainda a questão: "De que modo e por quais meios conseguirá a educação o seu fim ultimo, qual o de amoldar creaturas habilitadas para a vida intensa da época presente, capazes de vencer nas lutas de todos os dias?”. E ele mesmo responde: "fornecendo a todos os indivíduos o ensino primário gratuito de modo a formar e avigorar o civismo; ensinando a todos um ofício, uma habilidade manual; e por último promover ao maior número possível a cultura chamada clássica, como geradores de altruísmo" (SILVEIRA, 1918, p. 36). 
O segundo artigo encontra-se na seção de Pedagogia Prática, onde, assim como na revista $A$ Eschola Publica, são expostos por professores aulas e maneiras de ensinar conteúdos de diversas matérias. Redigido em dezembro de 1917 pelo professor José Juliano Netto ${ }^{15}$, o artigo intitulado "Trabalhos Manuais" discorre sobre como a matéria vem sendo ministrada nas escolas primárias e alguns apontamentos sobre como melhorar seu ensino.

O autor aborda que, devido à falta de obediência aos métodos, os resultados nos Grupos Escolares são completamente nulos e que, para obtê-los, devem ser estudados os processos de ensino e por isso os trabalhos devem ser "[...] de accôrdo com a capacidade dos alumnos, isto é, na ordem crescente do grão de adiantamento", ou seja, seguindo o método intuitivo de ensino (NETTO, 1917, p. 53).

Ao analisar especificamente aos conteúdos apresentados na matéria Trabalhos Manuais, Netto (1917) apresenta duas listas, uma aos meninos e outra às meninas, divididas nos quatro anos escolares, que exemplificam a distribuição dos trabalhos de modo a seguir o método na execução. Essas listas muito se assemelham às prescrições dos programas de 1905 e 1918, mas a profundidade do artigo está nas explicações da importância dos conteúdos: para o autor, a seção de carpintaria ou marcenaria sequer necessita de esclarecimentos sobre sua utilidade, pois já está comprovada; os de modelagem em cera, barro ou gesso trazem resultados quanto às culturas de habilidade, atenção e gosto artístico, como também na confecção de objetos auxiliares ao ensino de outras disciplinas, de modo a fornecer objetos de demonstração de lições de desenho, aritmética, geografia, geometria e ciências naturais e físicas.

Os dois artigos presentes na mesma revista expõem representações distintas sobre a finalidade do ensino dos Trabalhos Manuais, que de certo modo influenciam na relação com os saberes matemáticos. Ora é entendido que os Trabalhos Manuais se utilizam de saberes matemáticos para a formação do futuro trabalhador, ora os Trabalhos Manuais se constituem como método de ensino para os saberes geométricos, como o feitio de objetos e atividades que demonstrem e colaborem ao ensino. Assim, duas distintas finalidades são identificadas à referida matéria, tanto nos programas paulistas quanto nos artigos da Revista de Ensino.

Os altos índices de analfabetismo e a escassez de recursos no estado de São Paulo levaram o novo Diretor Geral da Instrução Pública, Sampaio Dória, a organizar uma Reforma na Instrução, regulamentada pelo Decreto $\mathrm{n}^{\mathrm{O}}$ 3356, de 31 de maio de 1921 (SÃO PAULO, 1921), que reduziu para dois anos o curso primário a ser ministrado nos Grupos Escolares (SOUZA, 2009). 
O texto original que discrimina as matérias a serem estudadas pelo programa de 1921 é restrito aos conteúdos, não apresenta qualquer método indicado para a aprendizagem, entretanto, o texto da Reforma discrimina a que método deve ser promovido o ensino:

Artigo 103.- Nas escolas primarias, o methodo natural do ensino é a iutição, a lição de cousas, o contexto da intelligencia com as realidades que se ensinam, mediante a observação e a expermintação, feitas pelos alumnos e orientadas pelo professor. São expressamente banidas da escola as tarefas de méra descrição, os processos que appellem exclusivamente para a memoria verbal, a substituição das cousas e factos pelos livros, que se devem apenas usar como auxiliares do ensino. (SÃO PAULO, 1921, grifo nosso).

O ensino dos Trabalhos Manuais nesse programa é prejudicado devido à diminuição do tempo escolar, só são propostos os conteúdos dos dois primeiros anos referentes aos programas de 1894, 1905 e 1918, ou seja, os trabalhos em madeira e cartonagem não estão presentes na nova normativa.

As lições no programa de 1921 se dedicam unicamente às dobraduras, tecelagens, alinhavos em papel, e modelagem de figuras geométricas, tratam-se somente de elementos básicos de iniciação ao trabalho com as mãos, às meninas são acrescidos os elementos básicos de costura, também conteúdos dos primeiros anos anteriores. A diminuição do período escolar pela metade de sua usual duração, com o intuito de alfabetizar mais alunos em menos tempo, remete a uma seleção de conteúdos vistos como pertinentes e importantes pelos legisladores que o instituíram. A finalidade desse programa reside então na alfabetização da população de maneira massificada, em que a formação de um ofício perde espaço. Seria o início de uma modificação da finalidade do ensino primário e, assim, acarretando uma única finalidade à matéria Trabalhos Manuais, auxiliar no ensino dos saberes matemáticos?

Coincidência ou não, Antonio Veiga (1921), professor da Escola Modelo Isolada, publica no mesmo ano, em 1921, no primeiro volume da Revista de Educação (Figura 3), um artigo intitulado “Um novo Trabalho Manual”. A revista é órgão da Escola Normal de Piracicaba e Escolas Anexas, e apresenta publicações de renomados nomes do ensino como Honorato Faustino - o diretor da Escola Normal de Piracicaba e anexas -, Antônio Pinto de Almeida Ferraz e Lourenço Filho - professores da Escola Normal -, Pedro Crem, Dário Brasil e Antônio dos Santos Veiga e Maria Graner - professores da Escola Modelo anexa à Escola Normal. 
Figura 3 - Capa da Revista de Educação

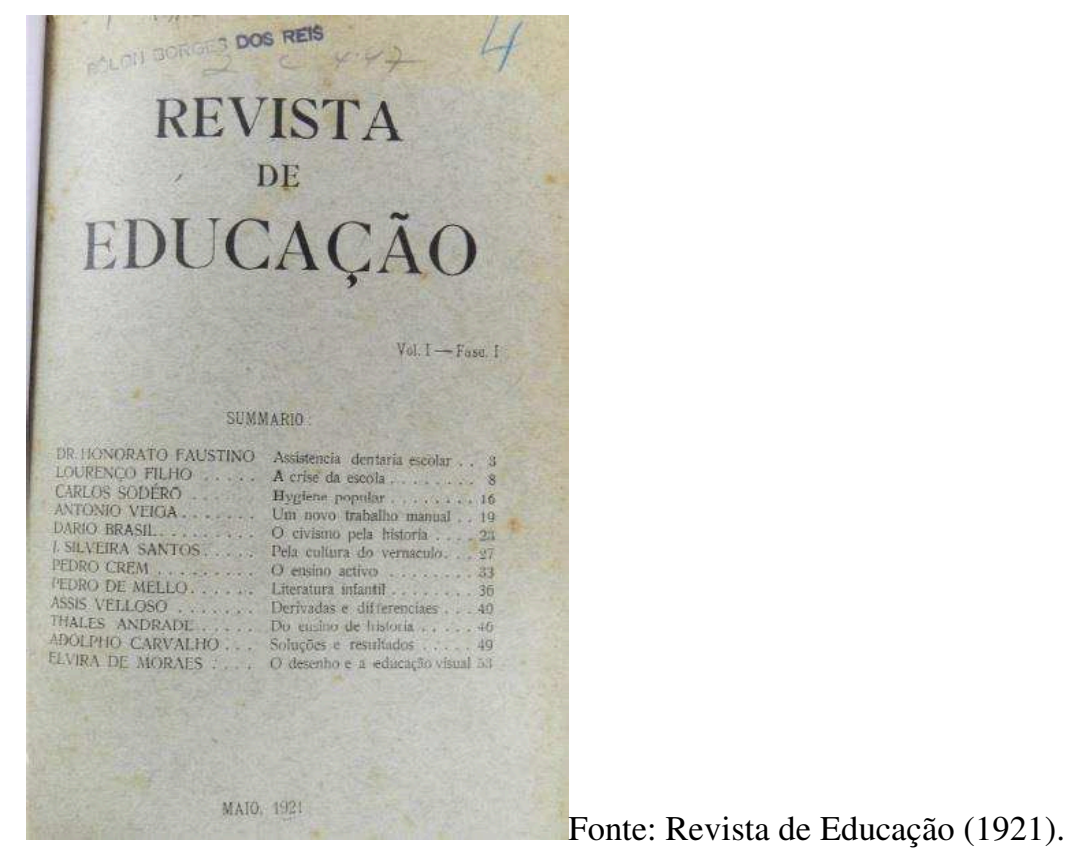

A novidade no Trabalho Manual apresentada por Veiga (1921) é o uso de serpentinas na criação de objetos conhecidos pelo aluno. Segundo o autor, a criança deve desenrolar a serpentina e depois enrolar segurando fortemente e construindo as formas desejadas, como, por exemplo, um relógio de parede (Figura 4).

Figura 4 - Trabalho Manual: Relógio de serpentina

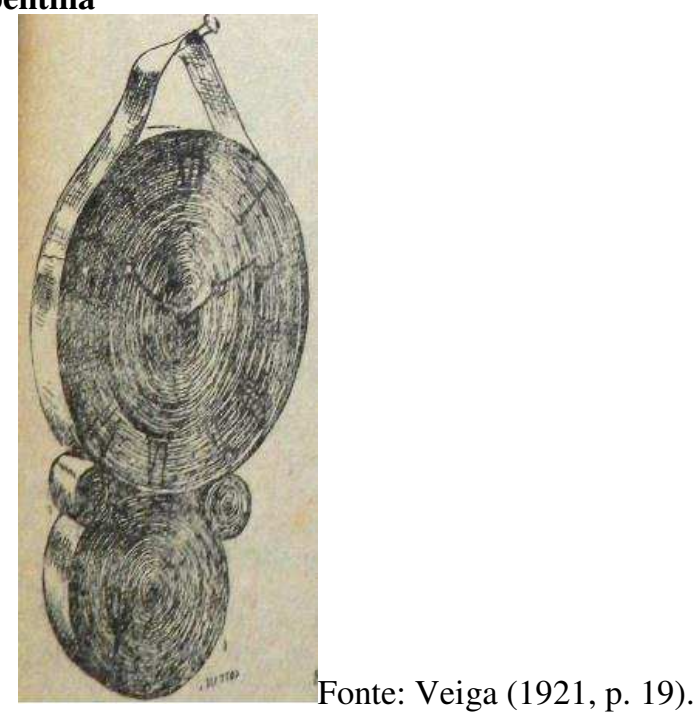

O novo não se aplica somente a esse diferente tipo de trabalho, mas também à visão que é posta sobre a importância dos Trabalhos Manuais. Em sua argumentação, Veiga (1921) aponta que além de 
cooperar para o desenvolvimento físico, intelectual e moral, os Trabalhos Manuais despertam espontaneamente a atenção nos alunos e a disposição moral para o trabalho. Ou seja, não se tem mais a finalidade de formação do futuro trabalhador, mas sim seu desenvolvimento moral, intelectual, físico e produtivo. O trabalho não é mais o objetivo desse ensino, mas, sim, a consequência.

Promulgado por um ato executivo, sem discussão anterior no Conselho Estadual, um novo programa é implantado por Pedro Voss em 1925 e aprovado pela Secretaria de Estado dos Negócios do Interior. Voltando à antiga formatação de quatro anos de duração, o programa apresenta estrutura bem diferenciada dos programas anteriores. Antes mesmo de apresentar os conteúdos a estudar, o programa de 1925 expressa indicações de como a matéria deve ser ensinada em confluência com a metodologia intuitiva e os conteúdos expressos posteriormente.

Com praticamente os mesmos conteúdos apresentados nos programas anteriores, mas com indicações muito distintas de como proceder com o ensino, os Trabalhos Manuais de 1925 parecem ter novas orientações. A transcrição do programa do quarto ano ajuda a compreender tais modificações:

Trabalhos manuais: Nesta classe desenvolveremos alguns exercícios da classe anterior, metodizando mais o ensino. Combinaremos, se for possível, os exercícios de desenho e modelagem e procuraremos seriar cuidadosamente as dificuldades nos ensinos em papel cartão e madeira. Os pontos e diversos trabalhos de costura serão feitos primeiro em peças de ensaio (paninhos de amostra) e aplicados depois em trabalhos de utilidade prática: lenços, guardanapos, toalhinhas, fronhas, camisas, aventais, roupas de criança, etc. Mas o trabalho manual das meninas, além dos trabalhos de costura e corte, comporta um certo numero de lições de conselhos, de exercícios, por meio dos quais a professora se prepara não a fazer um curso regular de economia doméstica, mas inspirar as meninas o sinal á ordem, fazendo-lhes adquirir as faculdades serias das donas de casa e pólas de sobreaviso contra os gastos frívolos e perigosos. Na escola em que fosse possível instalar algumas maquinas de costura, seria de grande utilidade ensinar não só a coser, como principalmente a bordar à maquina, trabalho de tão frequente aplicação na vida prática.

Programa:

1. Trabalhos de cartonagem: planificação, corte e colagem de poliedros e de objetos diversos - caixa com subdivisões internas, caixinha para palitos, caixa hexagonal, vasos, cachepôs, etc.

2. Pequenos trabalhos de arame: grades, etc.

3. Combinação de arame e madeira: gaiolas.

4. Modelar objetos, figuras, animais de fácil representação.

Talhar em madeira: régua, estaca, cabide simples, esquadro, cruz, simples, banquinho, etc. (SÃO PAULO, 1941).

Nesse programa, a divisão dos conteúdos para meninos ou meninas não é expresso tão nitidamente: nas indicações do programa são elencados que às meninas são acrescidos os trabalhos de 
costura e aprendizados do lar, entretanto, nos pontos do programa estes não aparecem. Os conteúdos do programa remetem veemente aos saberes geométricos na construção de poliedros e objetos que necessitam de conhecimentos geométricos para execução, tal como gaiolas, réguas, esquadros e até mesmo um banquinho. No entanto, não se pode ignorar a relação dos trabalhos em madeira e arame que remetem à formação do futuro trabalhador e às lições de costura e atividades do lar dedicadas às meninas.

O texto do programa de 1925 recebeu largas críticas por parte de reformadores participantes do Inquérito de 1926 sobre a instrução pública. O próprio Fernando de Azevedo ${ }^{16}$ (1937), organizador do inquérito, atacou o fato de que o sigilo na criação dos programas e a pressa na sua elaboração resultou em erros:

A volta a esse passado, preconisada como um estribilho pelos reformadores de 1925, é um triste symptoma dessa mentalidade sobrevivente, provadamente incapaz de tentar, por um surto innovador e em bases solidas, a ligação do passado e do presente com o futuro. [...] Os homens que insistem em plasmar a educação nos moldes de 1892, assemelham-se aos calvos que depois de terem experimentados todos os processos para fazer crescer os cabellos, acabam, - certos de deixar a impressão de que os têm, - por usar uma cabelleira postiça... A obra de Bernardino de Campos e Cesário Motta admiravel para o seu tempo, tem sido essa peruca enterrada até as orelhas pelos que não têm cabellos e não encontram meios de os fazer crescer [...]. (AZEVEDO, 1937, p. 154-155).

Neste trecho, Azevedo (1937) apresenta uma crítica ao programa de 1925, que, segundo ele, ainda se constitui sobre os moldes do programa de 1894, apontando que o ensino continua o mesmo de trinta anos antes.

\section{Algumas considerações}

De 1890 a 1930, os programas da escola primária paulista, seus autores e as revistas educacionais da época se apropriaram das prescrições do novo modelo educacional advindo com a Proclamação da República, a Pedagogia Moderna. A partir dele, cada um construiu sua representação do ideário do ensino primário ao Estado de São Paulo, mais especificamente aos Grupos Escolares.

Este estudo, com a intenção de construir uma representação histórica das propostas de ensino da matéria Trabalhos Manuais nas escolas primárias paulistas, com ênfase ao elo prático desenvolvido com o aluno e sua relação com os saberes matemáticos, no período de 1889 a 1930, analisou as 
normativas propostas pelos cinco programas de ensino que vigoraram na época e artigos de revistas pedagógicas, de modo a cotejar com a legislação.

A visível relação dos Trabalhos Manuais com os saberes matemáticos e o método intuitivo como precursor do ensino instigou a pergunta que se instalou desde o olhar ao primeiro programa de 1894: qual seria a finalidade dos saberes matemáticos presentes nos Trabalhos Manuais do curso primário paulista de 1890 a $1930 ?$

$\mathrm{Na}$ análise dos programas identificamos duas grandes finalidades ao ensino de Trabalhos Manuais: ora servem de apoio à demonstração e concretização dos saberes geométricos, como um exercício prático desses saberes, ora cumprem a função de formação do cidadão, do ensino de um ofício com distinção para o trabalho do homem e da mulher.

As finalidades mudam e uma mesma matéria pode atender a múltiplas finalidades ao longo dos anos escolares. Tudo leva a crer que há uma finalidade, a todos os alunos, que é a prática de modelagem como auxiliar em saberes geométricos de outras matérias, e uma segunda, distinta para cada gênero, de formação profissional.

A finalidade da escola primária na formação educacional e profissional do aluno, ressaltada desde o primeiro programa, juntamente com essa troca de relações entre os Trabalhos Manuais e os saberes matemáticos, permite-nos identificar que não é possível atribuir uma finalidade exclusivamente prática ao ensino dos Trabalhos Manuais, visto que esta matéria é muleta de suporte ao ensino dos saberes geométricos, como também não se atribui a ela uma finalidade unicamente intelectual, visto que atinge muitos outros campos do aluno, como o visual e o motor, além de ser uma matéria que prestigia a criatividade e intuição do aprendiz.

Desse modo, uma possível representação dos Trabalhos Manuais no curso primário paulista seria a compreensão das relações dessa matéria com os saberes matemáticos como uma via de mão dupla, em que um saber auxilia o outro e contribui para concretizar o ensino moral, físico, intelectual e profissional, de modo prático e intuitivo.

\section{Notas}

${ }^{1}$ Pedagogia Moderna é o termo empregado pela historiadora da educação Marta Maria Chagas de Carvalho (2002) para descrever o modelo escolar paulista iniciado em 1890 e caracterizado por uma pedagogia prática, em que a arte de ensinar era prescrita como uma boa imitação de modelos.

${ }^{2} \mathrm{O}$ estudo integra projeto maior intitulado "A dimensão prática e a escolarização dos saberes elementares geométricos", coordenado pela Prof. Dra. Maria Célia Leme da Silva e financiado pela Fundação de 
Amparo à Pesquisa do Estado de São Paulo (FAPESP), no qual serão analisados três diferentes olhares para as atividades práticas relacionadas aos saberes matemáticos: o primeiro, mais geral, aborda sobre os embates e diálogos entre as finalidades na constituição dos saberes elementares geométricos no Brasil e na França (sob responsabilidade da Prof. Dra. Maria Célia Leme da Silva); o segundo, trata-se do projeto de doutoramento de Deoclecia de Andrade Trindade, que se refere às artes de medir; e o último, investiga as transformações dos saberes matemáticos na matéria Trabalhos Manuais, projeto de doutoramento de Claudia Regina Boen Frizzarini.

${ }^{3}$ Roger Chartier (2002), em A história cultural: entre práticas e representações, fornece embasamento teórico e metodológico acerca da história cultural, à estes são acrescidos estudos de Chervel (1990) acerca da história das disciplinas escolares e das noções de finalidades reais e de objetivos, além dos conhecimentos de De Certeau $(2011,2012)$ relativo às práticas, estratégias e táticas.

${ }^{4}$ Rui Barbosa nasceu na Bahia em 5 de novembro de 1849, e em 1879 se fixou no Rio de Janeiro, ao ser eleito para a Assembleia Legislativa da Corte Imperial. Ganhou prestígio como orador, jurista e jornalista defensor das liberdades civis e foi, por duas vezes, candidato à Presidência da República. Notável orador e estudioso da língua portuguesa, foi membro fundador da Academia Brasileira de Letras, sendo presidente entre 1908 e 1919. Falece no dia $1^{\circ}$ de março de 1923 em Petrópolis, aos 73 anos de idade (BARBOSA, 1946).

${ }^{5}$ Todas as citações extraídas de livros, textos oficiais e artigos de revistas pedagógicas preservam a escrita da época.

${ }^{6}$ Oscar Thompson, Benedito Tolosa e Antonio Rodrigues Alves Pereira formaram-se pela Escola Normal da capital paulista na mesma turma, em 1891. Figuras influentes no ensino público de São Paulo, atuaram na Escola Modelo da capital e na Escola do Carmo, além de editorarem uma das mais influentes revistas do final do século XIX, A Eschola Publica (PINTO, 2000).

${ }^{7}$ O conceito de finalidade advém dos estudos de Chervel (1990, p. 188), que ao discutir sobre história das disciplinas escolares salienta que em diferentes épocas aparecem finalidades de todas as ordens impostas ao ensino e esse conjunto de finalidades "consigna à escola sua função educativa".

${ }^{8} \mathrm{O}$ conceito de apropriação é advindo dos estudos de Chartier (2010, p. 27), que o compreende como "uma história social das interpretações, remetidas para as suas determinações fundamentais (que são sociais, institucionais, culturais) e inscritas nas práticas específicas que as produzem".

${ }^{9}$ É apontado como auxílio, visto que a partir do programa de 1905 a modelagem passa a fazer parte dos conteúdos propostos em Trabalhos Manuais.

${ }^{10}$ O termo representação aqui apresentado se refere ao conceito de Chartier (2010, p. 49), que a compreende como uma apreensão do real que "permite vincular estreitamente as posições e as relações sociais com a maneira como os indivíduos e os grupos se percebem e percebem os demais".

${ }^{11}$ Alfredo Bresser da Silveira nasceu em São Paulo em 25 de março de 1872, formou-se pela Escola Normal de São Paulo em 1890, por 25 anos atuou exclusivamente como educador e tornou-se figura de destaque no magistério paulista. Foi professor e diretor da Segunda Escola Modelo da capital paulista e também diretor do Grupo Escolar do Carmo. Escreveu importantes literaturas escolares dedicadas ao manuscrito, desenho e trabalhos manuais. Ocupou a vice-presidência da Associação Beneficente do Professorado Público e o cargo de diretor da Escola Profissional Masculina. Faleceu aos 44 anos em 10 de abril de 1916 (ROCCO, 1946).

12 Ramon Roca Dordal nasceu em 1854 na Espanha e veio ao Brasil com 19 anos, trabalhou como desenhista na estrada de ferro do Rio de Janeiro e como tipógrafo no Jornal do Commercio. Em 1886 matriculou-se na Escola Normal de São Paulo e depois de diplomado ocupou a $1^{\text {a }}$ cadeira de Itatiba, posteriormente tornou-se $1^{\circ}$ diretor do Grupo Escolar Cel. "Júlio César", lecionou na $2^{\mathrm{a}}$ escola modelo de São Paulo, chamada "Escola Modelo do Carmo", como auxiliar de Alfredo Bresser por 10 anos. Exerceu cargo de $1^{\circ}$ Grupo Escolar do Braz e foi colaborador ativo das revistas A Eschola Publica e Revista de Ensino. Foi inspetor escolar na cidade de São Paulo até 1919 e faleceu em 1938 com 84 anos (PASQUIM, 2010).

${ }^{13}$ Horácio Manley Lane nasceu na cidade de Readfield, estado de Maine, nos Estados Unidos da América. Lane desembarcou no Brasil e iniciou-se no Magistério no Colégio João Kopke. Em 1884, atendendo à 
solicitação do Reverendo Chamberlain, assume a direção da Escola Americana, que depois receberia a denominação de Colégio Protestante, posteriormente Mackenzie College, e mais tarde Instituto Mackenzie, entidade da qual foi um dos fundadores. Dois anos depois tornar-se-ia presidente da instituição. Sua experiência à frente do Mackenzie College era unanimemente reconhecida. No ano de 1890, Bernardino de Campos, presidente do Estado de São Paulo, juntamente com Cezário Motta, secretário da Educação, e Caetano de Campos resolveram dinamizar a instrução pública estadual, organizando-a nos moldes da moderna pedagogia implantada na Escola Americana. Na ocasião, Lane foi convidado por Cezário Motta para ocupar o posto de Consultor Educacional de Ensino Público. Informação disponível em: <http://manleylane.blogspot.com.br/>.

${ }^{14}$ Nascido em Silveiras, estado São Paulo, em 21 de Junho de 1883, Carlos da Silveira entre os anos de 1900 a 1903 cursou e se diplomou pela Antiga Escola Normal da Praça, fez ainda preparatórios no curso Anexo. Bacharelou-se em Ciências Jurídicas e Sociais na Faculdade de Direito do Largo de São Francisco em 1909. Foi professor e diretor de diversas escolas no estado e Secretário da Escola Normal Secundária de São Carlos em 1912, tornando-se lente de Psicologia Experimental, Pedagogia e Educação Cívica na Escola Normal Secundária de São Paulo e lente substituto de Psicologia e Pedagogia (CHIARI, 2013).

${ }^{15}$ José Juliano Netto nasceu na cidade de Itatiba, estado de São Paulo, em 15 de abril de 1890. Cursou o primário no Grupo Escolar de Serra Negra e ingressou depois na Escola Complementar de Campinas, onde recebeu o diploma de professor primário com a melhor média. Iniciou o magistério primário 1908, como substituto no Grupo Escolar "Luiz Leite" em Amparo. Em 1915 foi removido a pedido, para o Grupo Escolar "Dr. Padua Salles" de Jaú, onde continuou sua carreira jornalística. Informação disponível em: <http://www.cdcc.sc.usp.br/julianoneto/hist_patrono.html>.

${ }^{16}$ Fernando de Azevedo (1894-1974) foi um dos mais importantes representantes do movimento da Escola Nova no Brasil. Embora graduado em Direito, tornou-se especialista em educação física, crítico literário, profissional da educação e cientista social. Foi o responsável pela redação do Manifesto dos Pioneiros da Educação Nova em 1932 (SOUZA, 2009).

\section{REFERÊNCIAS}

AZEVEDO, Fernando de. A educação pública em São Paulo: problemas e discussões. Inquérito para "O Estado de S. Paulo", em 1926. São Paulo: Cia Editora Nacional, 1937.

BARBOSA, Rui. Reforma do Ensino Primário e várias Instituições Complementares da Instrução Pública. Rio de Janeiro: Ministério da Educação e Saúde, 1946. 10 v. (Obras Completas de Rui Barbosa).

BRASIL. Deccreto ${ }^{\circ}$, de 19 de abril de 1819, Reforma o ensino primario e secundario no municipio da Côrte e o superior em todo o Imperio. Coleção de Leis do Império do Brasil, Rio de Janeiro, 1879. Disponível em: <http://www2.camara.leg.br/legin/fed/decret/1824-1899/decreto-7247-19-abril-1879547933-publicacaooriginal-62862-pe.html>. Acesso em: 3 abr. 2015.

CARVALHO, Marta Maria Chagas de. Pedagogia da Escola nova, produção da natureza infantil e controle doutrinário da escola. In: FREITAS, Marcos Cezar de; KUHLMANN JUNIOR, Moysés (Org.). Os Intelectuais na História da Infância. São Paulo: Cortez, 2002. p. 373-409. 
CARVALHO, Marta Maria Chagas de. Pedagogia moderna, pedagogia da escola nova e modelo escolar paulista. In: CARVALHO, Marta Maria Chagas de; PINTASSILGO, Joaquim (Org.). Modelos culturais, saberes pedagógicos, instituições educacionais. São Paulo: Edusp; Fapesp, 2011. p. 185-212. CHARTIER, Roger. A história cultural: entre práticas e representações. Lisboa: Difel; Rio de Janeiro: Bertrand Brasil S.A., 2002.

CHARTIER, Roger. A história ou a leitura do tempo. 2. ed. Tradução de Cristina Antunes. Belo Horizonte: Autêntica, 2010.

CHERVEL, André. História das disciplinas escolares: reflexões sobre um campo de pesquisa. Teoria \& Educação, Porto Alegre, RS, n. 2, 1990.

CHIARI, C. M. Educação, Pedagogia e Psicologia no pensamento educacional de Carlos da Silveira. In: CONGRESSO BRASILEIRO DE HISTÓRIA DA EDUCAÇÃO, 7., 2013, Cuiabá. Anais... Cuiabá, MT: SBHE, 2013.

DE CERTEAU, Michel. A escrita da história. Tradução de Maria de Lourdes Menezes. 3. ed. Rio de Janeiro: Forense, 2011.

DE CERTEAU, Michel. A invenção do cotidiano: artes de fazer. Tradução de Ephraim Ferreira Alves. 19. ed. Petrópolis, RJ: Vozes, 2012.

FRIZZARINI, Claudia Regina Boen. Do ensino intuitivo para a escola ativa: os saberes geométricos nos programas do curso primário paulista, 1890-1950. 2014. 160 f. Dissertação (Mestrado em Educação e Saúde na Infância e na Adolescência) - Universidade Federal de São Paulo, Guarulhos, SP, 2014.

LEBEAUME, Joël. Travail manuel, technologie. In: JACQUET-FRANCILLON, François; D'ENFERT, Renaud; LOEFFEL, Laurence (Dir.). Une histoire de l'école: anthologie de l'éducation et de l'enseignement en France XVIIIe-XXe siècle. Paris: Retz, 2010. p. 359-366.

NETTO, José Juliano. Trabalhos Manuais. Revista de Ensino, Jahú, v. 1, n. 3-4, p. 53-60, dez. 1917. Disponível em: <https://repositorio.ufsc.br/xmlui/handle/123456789/130205>. Acesso em: 3 abr. 2015.

PASQUIM, Franciele Ruiz. Ramon Roca Dordal (1854-1938) e Carlos Alberto Gomes Cardim (18751938) na história da alfabetização no Brasil. Revista de Iniciação Científica da FFC, Marília, SP, v. 10, p.1-14, 2010.

PINHEIRO, Nara Vilma Lima. Escolas de práticas pedagógicas inovadoras: intuição, escolanovismo e matemática moderna nos primeiros anos escolares. 2013. 155 p. Dissertação (Mestrado em Educação e Saúde na Infância e na Adolescência) - Universidade Federal de São Paulo, Guarulhos, SP, 2013.

PINTO, Adriana Aparecida. A Eschola Pública: uma análise da Pedagogia Paulista no Período Republicano. In: CONGRESSO BRASILEIRO DE HISTÓRIA DA EDUCAÇÃO, 1., 2000, Rio de Janeiro. Anais... Campinas, SP: Autores Associados, 2000. p. 151-153. 
REVISTA A Eschola Publica. São Paulo: Typografia Industrial de São Paulo, 1896. Disponível em: <https://repositorio.ufsc.br/xmlui/handle/123456789/126749>. Acesso em: 3 abr. 2015.

REVISTA de Educação. São Paulo: Typografia do Jornal de Piracicaba, 1921. Disponível em: <https://repositorio.ufsc.br/xmlui/handle/123456789/127296>. Acesso em: 3 abr. 2015.

REVISTA de Ensino: Orgam da Associação Beneficente do Professorado Publico de São Paulo. São Paulo: Typografia do Diário Oficial, 1918. Disponível em:

$<$ https://repositorio.ufsc.br/xmlui/handle/123456789/130205>. Acesso em: 3 abr. 2015.

ROCCO, Salvador (Org.). Poliantéia comemorativa: 1846-1946, primeiro centenário do ensino normal de São Paulo. São Paulo: Gráfica Bréscia, 1946.

SÃO PAULO. Lei $n^{\circ} 88$, de 8 de setembro de 1892. Reforma a instrução pública do Estado. Assembleia Legislativa do Estado de São Paulo, São Paulo, 1892. Disponível em:

<http://www.al.sp.gov.br/repositorio/legislacao/lei/1892/lei-88-08.09.1892.html>. Acesso em: 3 abr.

2015.

SÃO PAULO. Decreto n ${ }^{\circ} 248$, de 26 de julho de 1894. Aprova o regimento interno das escolas públicas. Assembleia Legislativa do Estado de São Paulo, São Paulo, 1894. Disponível em: <http://repositorio.ufsc.br/xmlui/handle/123456789/99544>. Acesso em: 3 abr. 2015.

SÃO PAULO. Decreto n ${ }^{\circ} 1281$, de 24 de abril de 1905. Aprova e manda observar o programa de ensino para a escola modelo e para os grupos escolares. Assembleia Legislativa do Estado de São Paulo, São Paulo, 1905. Disponível em: <http://repositorio.ufsc.br/xmlui/handle/123456789/99554>. Acesso em: 3 abr. 2015.

SÃO PAULO. Decreto n ${ }^{\circ} 2.944$, de 8 de agosto de 1918. Aprova o regulamento para a execução da Lei $\mathrm{n}^{\circ} 1579$, de 19.12.1917, que estabelece diversas disposições sobre a instrução pública do Estado. Assembleia Legislativa do Estado de São Paulo, São Paulo, 1918. Disponível em: <http://repositorio.ufsc.br/xmlui/handle/123456789/99555>. Acesso em: 3 abr. 2015.

SÃO PAULO. Decreto n ${ }^{\circ} 3356$, de 31 de maio de 1921. Regulamenta a Lei $\mathrm{n}^{\circ} 1750$, de 8 de dezembro de 1920, que reforma a instrução pública. Assembleia Legislativa do Estado de São Paulo, São Paulo, 1921. Disponível em: <http://repositorio.ufsc.br/xmlui/handle/123456789/99556>. Acesso em: 3 abr. 2015.

SÃO PAULO. Departamento de Educação. Secretaria dos Negócios da Educação e Saúde Pública. Programa de Ensino para as Escolas Primárias. São Paulo: Serviço Técnico de Publicidade, 1941. Disponível em: <http://repositorio.ufsc.br/xmlui/handle/123456789/99651>. Acesso em: 3 abr. 2015.

SHIEH, Cynthia Lushiuen. O que ensinar nas diferentes escolas públicas primárias paulistas: um estudo sobre os programas de ensino (1887-1929). 2010. 184 f. Dissertação (Mestrado em Educação) Universidade de São Paulo, São Paulo, 2010. 
SILVEIRA, Carlos da. Da educação e dos educadores. Revista de Ensino, São Paulo, v. 1, n. 3-4, p. 3541, mar. 1918. Disponível em: <https://repositorio.ufsc.br/xmlui/handle/123456789/130205>. Acesso em: 3 abr. 2015.

SOUZA, Rosa Fátima de. Inovação educacional no século XIX: a construção do currículo da escola primária no Brasil. Cadernos do CEDES, Campinas, SP, v. 51, p. 33-44, 2000.

SOUZA, Rosa Fátima de. Alicerces da Pátria: história da escola primária no estado de São Paulo (1890-1976). Campinas, SP: Mercado de Letras, 2009.

VEIGA, Antonio. O trabalho manual e o ensino intuitivo. Revista de Educação, São Paulo, v. 1, n. 2, p. 135-139, set. 1921. Disponível em: <https://repositorio.ufsc.br/xmlui/handle/123456789/127296>. Acesso em: 3 abr. 2015.

ZANATTA, Beatriz Aparecida. O legado de Pestalozzi, Herbert e Dewey para as práticas pedagógicas escolares. Revista Teoria e Prática da Educação, Maringá, PR, v. 15, n. 1, p. 105-112, jan./abr. 2012. Disponível em: <http://periodicos.uem.br/ojs/index.php/TeorPratEduc/article/view/18569>. Acesso em: 29 nov. 2015. 
The active teaching of Craft in São Paulo primary school: a study of the schooling of mathematical knowledge

\begin{abstract}
This article aims to build a first representation on the teaching of the Crafts as a subject in primary school of São Paulo from its relationship with mathematical knowledge. The study supported by the theoretical and methodological tools of Cultural History has two main purposes, which relate to mathematical knowledge, attributed to the school for these matters: first, the Crafts function is to assist the process of understanding the geometric knowledge, which functions as a "teaching method" to learn mathematical knowledge; in the second, the Craft as an use of mathematical knowledge studied in other subjects for the formation of worker, for a craft to the student. Thereby, a representation of Craft in São Paulo primary school would be the understanding of the relationship of this subject with the mathematical knowledge as a two-way street, where one knowledge helps to know the other and contributes to achieve moral, physical, intellectual, and professional education, in a practical and intuitive way.
\end{abstract}

Keywords: Crafts. Primary School. Education Purposes.

\section{L'enseignement actif du Travail Manuel à l'école primaire de São Paulo: une étude de la scolarité à la connaissance mathématique}

\section{Résumé}

Cet article vise à construire une première représentation sur l'enseignement de l'objet le Travail Manuel dans l'école primaire de São Paulo depuis sa relation avec la connaissance mathématique. L'étude soutenue par les outils théoriques et méthodologiques de l'Histoire Culturelle assignés deux principaux objectifs qui se rapportent à la connaissance mathématique, attribués à l'école pour ces questions: d'abord, la fonction du Travail Manuel est d'aider le processus de compréhension de la connaissance géométrique, fonctionne comme une "méthode d'enseignement" d'apprendre la connaissance mathématique; dans le second, le Travail Manuel comme une application des connaissances mathématiques dans d'autres sujets étudiés pour la formation des travailleurs, dans un métier à l'étudiant. Ainsi, une représentation du Travail Manuel à l'école primaire de São Paulo serait la compréhension de la relation de cette question avec la connaissance mathématique comme une voie à double sens, où l'on aide à connaître les uns les autres et contribue à la réalisation de l'éducation morale, physique, intellectuel et professionnel, de manière pratique et intuitive.

Mots-clés: Travaux Manuels. Enseignement Primaire. Fins d'Éducation.

Enviado em: 22/5/2015

Aprovado em: 30/11/2015

Maria Célia Leme da Silva

E-mail: mcelialeme@gmail.com 